\title{
Origin and Meiotic Behaviour of Two Multiple Interchange Trisomics in Pearl Millet (Pennisetum americanum L. Leeke)
}

\author{
Alice K. Vari and J. G. Bhowal ${ }^{1}$ \\ Biotechnology Centre, Indian Agricultural Research Institute, \\ New Delhi-12, India
}

Accepted April 20, 1990

Chromosomal aberrations like interchanges and translocations are useful cytogenetic tools which have been utilized extensively in crop improvement progiamme. They are also important from the evolutionary point of view as they are known to bring about karyotypic changes which in the long run may have some adaptive advantages over natural populations. Chromosomal interchanges, both induced and spontaneous origin, have been reported in pearl millet (Powel and Barton 1969, Jauhar 1974, Tyagi 1976). Interchange trisomics have been reported by Manga (1977), Minocha and Barr (1976), Rao et al. (1977), and others. In the present study the origin and meiotic behaviour of two multiple interchange trisomics have been discussed.

\section{Materials and methods}

The two multiple interchange trisomics $(2 n=15)$ were isolated in the progeny of two tertiary interchange trisomics which in turn were obtained from some of the primary trisomics reported earlier (Vari and Bhowal 1986). The plants were raised in pots along with normal diploids and trisomics. For meiotic studies young spikes were collected and fixed in 3:1 alcohol acetic acid and slides were made by the usual acetocarmine staining method.

\section{Results}

\section{Origin and morphology}

The parental trisomics from which the multiple interchange trisomics were isolated were tertiary interchange trisomics as they showed in diakinesis a chromosome association of 1 " $5^{\mathrm{II}}$ or $\odot 4+5^{\mathrm{II}}+1^{\mathrm{I}}$. The multiple interchange trisomic designated as $29-2$ had all the chromosomes while the other $31-7$ had at least seven chromosomes involved in translocation. The other sister plants were either tertiary trisomics, tertiary interchanges or diploids with translocations.

The two multiple interchanges differed from the disomics as well as the other trisomic types in their morphological characters. They were short in stature, less vigorous with slender stem and narrow short stiff leaves having profuse hairs on the lamina and petiole. They flowered very late compared to disomics and parental trisomic .

\section{Cytology}

The frequency of different type of chromosome association at diakinesis is given in Table 1. In 29-2 association involving all the fifteen chromosomes were observed occasionally (Fig. 1) indicating that it is a multiple interchange trisomic which involved all the chromosomes. In 31-7 the maximum number of chromosomes involved in translocation was seven as it showed a

\footnotetext{
${ }^{1}$ Division of Genetics, I.A.R.I., New Delhi-110012
} 


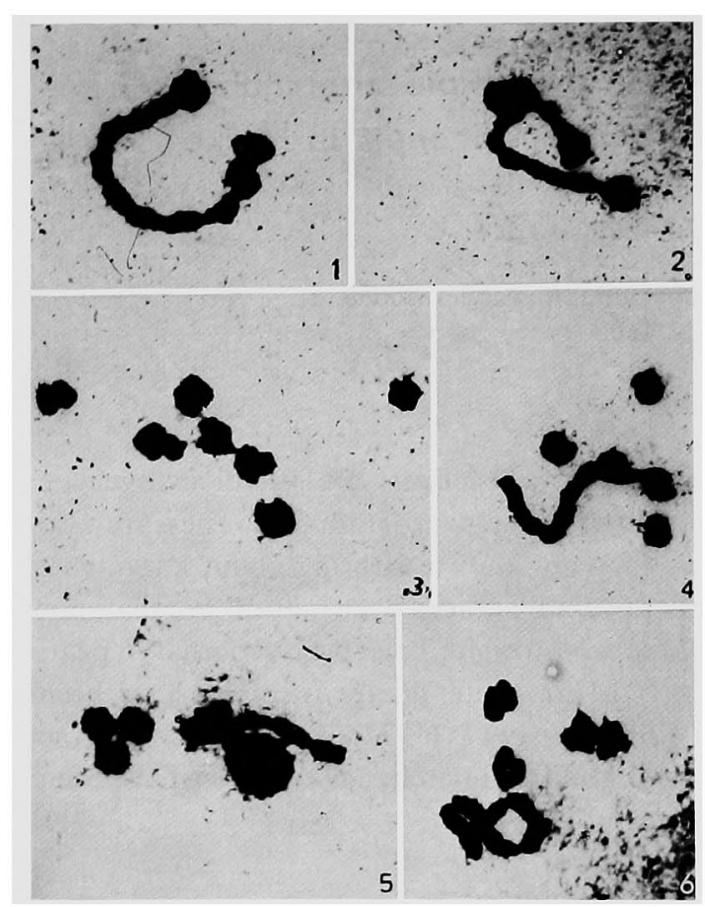

Figs. 1-6. Chromosome associations at diakinesis in multiple interchanges. 1,2, Multivalent involving 15 chromosomes in $29-2$. $3,1^{\mathrm{III}}+6^{\mathrm{II}}$ association in $29-2$. $4,1^{\mathrm{IX}}+3^{\mathrm{II}}$ association in $29-2$. 5, Bivalents showing interconnections in 29-2. $6,1^{\mathrm{VII}}+4^{\mathrm{II}}$ association in $31-7$. chain of seven chromosomes (Fig. 6). In both the interchanges the most common type of association observed was $1^{\mathrm{VII}}+4^{\mathrm{II}}$. In 27-2 associations like a $\odot 7+4^{\text {II }}, \odot 5+5^{\text {II }}$ and $1^{\mathrm{IX}}+3^{\mathrm{II}}$ (Fig. 4) were also observed.

In 29-2 very often at diakinesis when bivalents were present they tend to show some interconnections (Fig. 3). Very often varying number of bivalents were found attached to the multivalents (Figs. 2 and 4) or the bivalents were found to be in groups of 2 or 3 with interconnections (Fig. 5). Out of 115 PMCs studied critically only one case was found in which all the seven bivalents remained separate.

The multivalent formation in the interchanges resulted in varying types of abnormalities in later stages of meiosis (Table 2). Only about $50 \%$ of the PMCs showed normal $7 / 8$ anaphase disjunction. PMCs having one or two laggards, $9 / 6$ disjunction were quite common in both the intercharges. Tetrads with micronuclei varying from 1 to 4 were observed in about $25 \%$ of the cells. The pollen fetility was reduced to $39.39 \%$ in $29-2$ and $45.58 \%$ in 31-7. The seed fertility was very low in both interchanges as

Table 1. Chromosome associations at diakinesis in multiple interchange trisomics

\begin{tabular}{ccc}
\hline \hline $\begin{array}{c}\text { Type of chromosome } \\
\text { association }\end{array}$ & $\%$ of cells in $29-2$ & \% of cells in 31-7 \\
\hline $1^{\mathrm{XIV}}+0^{\mathrm{II}}$ & 1.70 & 0 \\
$1^{\mathrm{III}}+4^{\mathrm{II}}$ & 46.35 & 46.08 \\
$1^{\mathrm{V}}+5^{\mathrm{II}}$ & 26.83 & 20.08 \\
$1^{\mathrm{IV}}+4^{\mathrm{II}}$ & 21.96 & 0 \\
$1^{\mathrm{III}}+6^{\mathrm{II}}$ & 2.43 & 26.00 \\
$7^{\mathrm{II}}+1^{\mathrm{I}}$ & 2.43 & 6.15 \\
PMCs studied & 164 & 115 \\
\hline
\end{tabular}

Table 2. A-1 disjunction in multiple interchange trisomics

\begin{tabular}{ccc}
\hline \hline Type of disjunction & $\begin{array}{c}\text { \% of cells in 29-2 } \\
\text { interchange }\end{array}$ & $\begin{array}{c}\text { \% of cells in 31-7 } \\
\text { interchange }\end{array}$ \\
\hline $7-8$ & 50.0 & 57.3 \\
$7-1-7$ & 22.8 & 6.5 \\
$7-2-6$ & 6.4 & 10.0 \\
$9-6$ & 14.8 & 23.5 \\
$8-1-6$ & 6.0 & - \\
No. PMCs studied & 250 & 200 \\
\hline
\end{tabular}


they produced only $10-15$ seeds in few of the panicles.

\section{Discussion}

Multiple interchanges involving all the chromosomes have been induced in diploid pearl millet by various authors. Minocha and Brar (1976) produced a multiple interchange trisomics involving seven chromsomes by intercrossing two interchanges. In the present study multiple interchange trisomic involving all the fifteen chromosomes were obtained in the progeny of a tertiary interchange trisomic suggesting that aneuploidy (trisomy) with translocation could induce further chromosome alterations in Pennisetum americanum.

Structural changes associated with aneuploidy has been reported as early as 1928 by Belling and Blakeslee in Datura. Subsequently in crop like Zea (Clark and Copeland 1940), Lilium and Hyacinthus (Brock 1954 and 1955), Trillium (Rutishauser 1956) etc. and it has been shown that translocations occur more frequently in triploids than in diploids. Ising (1969) in Cyrtanthus observed that aneuploidy especially trisomics of species hybrids are more effective in producing new chromosomal changes. Several theories have been put forward as the cause of the spontaneous chromosome alteration in aneuploids as well as in diploids. Chromosome breakage in aneuploid may be due to the genetic imbalance caused by certain automutagenic substance or due to the deficiency of radical substances (Heneen 1963).

In Cyrtanthus, Ising (1969) observed that certain trisomics give higher frequency of breakges which he suggested may be due to several duplicated segments or they may generate more automutagenic substances which may be necessary for primary single strand breaks. It may be suggested that whatever the cause of chromosome breakage in aneuploids of a crop like Pennisetum, aneuploidy together with translocations of spontaneous nature could produce structural changes in chromosomes and could alter the basic karyotype that may be important on the evolutionary point of view.

The meiotic behaviour especially the chromosome associations in the multiple interchange 29-2 was found to be of interest. Though from Fig. 1 and 2 it is evident that all the chromosomes in the complement was involved in translocation the frequency of cells having this type of association was very low. The high frequency of PMCs having $1^{\mathrm{VII}}+4^{\mathrm{II}}$ type association indicates that very often only seven of the interchanged chromosomes could take part in pairing and others remained separate to form bivalents. Also it was interesting to note that though there was possibility of forming more than one multivalent per cell only one multivalent per cell was present except in cases where one quadrivalent and one trivalent per cell was observed. Another observation peculiar to 29-2 was the secondary associations or interconnections between the bivalents observed. Secondary association of chromosomes has been reported in many of the diploid species and it has been interpreted as the result of modified chromosome rearrangement such as duplication, interchange etc. by Stebbins (1950), Darlington (1928), Darlington and Moffot (1930). Lawrence (1931) and Riley (1960) consider it as direct evidence of remote affinity between chromosomes. In the present study it may be suggested that complete homology between chromosomes resulted in bivalent formation and the interconnections between bivalents represents segmental homology due to interchanges. It may be possible that the genetic homology between some of the interchanged chromosomes may not be sufficient enough to ensure complete pairing and early terminalization of chiasma has taken place and they remained as bivalents but still maintaining their affinity to the multivalent or to other bivalents.

In earlier studies involving multiple interchanges high frequency of cells having multivalents have been observed. Sukdev et al. (1985) reported a maximum association of 10 chromosomes in about $66.3 \%$ cells in a multiple interchange of Pennisetum. In induced seg- 
mental interchanges of Pennisetum Lal and Srinivaschar (1979) observed almost $100 \%$ of the PMCs with quadrivalents or higher multivalents. It may be suggested that multiple interchanges with reduced frequency of multivalents per cell may be more advantageous as they may show less abnormalities in later stages of meiosis which in turn could reduce the gametic sterility.

\section{Summary}

Two multiple interchange trisomics one involving all the fifteen chromosomes and other at least seven chromosomes were isolated in the progeny of two tertiary interchange trisomics of pearl millet (Penninsetum americanum $(2 \mathrm{n}=14)$ ). The study of chromosome association of diakinesis in these multiple interchanges showed varying frequencies and type of multivalent formations followed by abnormalities in later stages of meiosis. Secondary association of bivalents was quite frequent in one of the interchange. Aneuploidy together with translocation as the probable cause of further chromosome interchanges has been discussed on the light of the present investigation.

\section{References}

Belling, J. and Blakeslee, A. F. 1928. On the attachment of non-homologous chromosomes at the reduction division in certain 25-chromosome Daturas. Proc. Nat. Acad. Sci. 12: 7-11.

Brock, R. D. 1954. Spontaneous chromosome breakage in Lilium endosperm. Ann. Bot. N.S. 18: 7-14.

- 1955. Chromosome balance and endosperm failure in Hyacinthus. Heridity 9: 199-222.

Clark, F. J. and Copeland, F. G. 1940. Chromosome aberrations in the endosperm of maize. Am. J. Bot. 27: $247-251$.

Darlington, C. D. 1928. Studies in Prumus I and II. J. Gent. 19: 215.

- and Moffet, A. A. 1930. Primary and secondary chromosome balance in Pyrus. J. Genet. 22: 129-151.

Heneen, W. K. 1963. Extensive chromosome breakage occurring spontaneously in a certain individual of Elymus faretus (=Agropyron junceum). Heriditas 49: 1-32.

Ising, G. 1969. Cytogenetic studies in Cyrtanthus III. Aneuploidy and structural chromosome changes. Heriditas. 63: 213-256.

Jauhar, P. P. 1974. Induction of multiple chromosome interchanges in pearl millet, Pennisetum typhoides L. Theor. Appl. Genet. 44: 58-62.

Lal, J. and Srinivaschar, D. 1979. Induction of segmental interchanges in pearl millet (Pennisetum typhoides). Theor. Appl. Genet. 54: 27-32.

Lawrence, W. J. 1931. Secondary association of chromosomes. Cytologia 2: 353-384.

Manga, V. 1977. Interchange trisomics in pearl millet. Experentia. 3: 1581-1582.

Minocha, J. L. and Brar, D. S. 1976. Multiple interchange trisomics in pearl millet. Ind. J. Genet. 36: 153-155.

Narasinga Rao, P., S. R. L. Subha Rao. and H. V. Narayanana Rao. 1977. Two interchange trisomics in pearl millet. Curr. Sci. 46: 314-315.

Powel, J. B. and Barton, J. W. 1969. Chromosome interchanges of spontaneous origin in pearl millet Pennisetum typhoides. Crop Sci. 9: 252-253.

Riely, R. 1960. The secondary pairing of bivalents with genetically similar chromosomes. Nature 185: 751752.

Rutishauser, A. 1956. Chromosome distribution and spontaneous chromsome breakage in hybrid endosperms. Chromosoma 8: $317-340$.

Stebbins, G. L. 1950. Variation and Evolution in Plants. Columbia Univ. Press, New York.

Sukadev, P., Janake, P. S., Murthy, J. V.S. V., Rao, M. V.S. and Manga, V. 1985. Meiotic behaviour of multiple interchange heterozygote in pearl millet. Cytologia 50:347-350.

Tyagi, B. R. 1976. Synthesis of complex interchange stocks in pearl millet. Nucleus 19: 58-63.

Vari, A. K. and Bhowal, J. G. 1986. Studies on the trisomics of Pennisetum americanum L. Leeke. Morphological and cytological behaviour of primary trisomics. Cytologia 51: 679-692. 